\title{
41. Effect of Dimethylsulfoxide on the Crystallization of Aspergillus niger Proteinase A
}

\author{
By Hidemi MatsuZaki, ${ }^{*)}$ So IWATA, **) Toru Hamaya,***) \\ Toshio Takizawa, ${ }^{* *)}$ Masaru Tanokura, ${ }^{*)}$ and Kenji TAKAhashi*) \\ (Communicated by Setsuro Ebashi, M. J. A., Dec. 12, 1991)
}

\begin{abstract}
Proteinase A from Aspergillus niger var. macrosporus is a non-pepsintype acid proteinase, whose catalytic site and enzymatic mechanism remain to be clarified. As the first step toward elucidating its three-dimensional structure by X-ray crystallography, proteinase A was crystallized in ammonium sulfate solutions by the hanging-drop vapor diffusion method. In the absence of an organic solvent, only the aggregates of long, thin needles were formed. On the other hand, thicker rodlike single crystals were grown at around $\mathrm{pH} 1.75$ when dimethylsulfoxide (DMSO) was added to a concentration of around $5 \%$. The single crystals of proteinase A thus obtained were suitable for X-ray diffraction measurements with a precession camera.
\end{abstract}

Key words: Crystallization; A. niger proteinase A; DMSO.

Introduction. Proteinase A is one of the two acid proteinases secreted by the fungus Aspergillus niger var. macrosporus, ${ }^{1)}$ and belongs to a group of non-pepsin-type acid proteinases as judged from its clear differences in various properties from the ordinary aspartic proteinase family, including pepsin, A. niger acid proteinase B, renin, and human immunodeficiency virus proteinase. ${ }^{2-6)}$ Proteinase $\mathrm{A}$ is rather insensitive to common, specific inhibitors for the pepsin-type aspartic proteinases. ${ }^{2)}$ It has a relative molecular mass of $22,300,{ }^{4), 7}$ about half the size of ordinary pepsin-type aspartic proteinases $\left(M_{\mathrm{r}} \sim 35,000\right)$, and shows fairly different substrate specificity. ${ }^{33,8)}$ The amino acid sequence determination ${ }^{4), 6)}$ revealed that no proteins in the GenBank database are homologous with proteinase A except for Scytalidium lignicolum proteinase $\mathrm{B}^{9)}$ that shows about $50 \%$ identity. Proteinase A has no consensus sequences, i.e., Asp-Thr/Ser-Gly, including the active-site aspartic acid residues, present in the family of pepsin-type aspartic proteinases. It, thus, remains to be elucidated which residues participate in the catalysis and how the mechanism operates. In order to approach this question, it is of utmost importance to elucidate the three-dimensional structure of the enzyme.

In the present study, we examined various conditions to grow the crystals of proteinase A for X-ray crystallography with special attention to the effect of dimethylsulfoxide (DMSO).

Materials and methods. Proteinase A was purified from the crude enzyme mixture obtained from the culture medium of Aspergillus niger var. macrosporus by repeated chromatography on DEAE-Toyopearl $650 \mathrm{~S}$ columns. The hanging-drop vapor diffusion method was employed at $4^{\circ} \mathrm{C}$ and $25^{\circ} \mathrm{C}$ to survey crystallization conditions, with ammonium sulfate, over the range of $\mathrm{pH}$ values from 1.0 to 3.0 at every $0.25 \mathrm{pH}$ unit. The

*) Department of Biophysics and Biochemistry, Faculty of Science, The University of Tokyo, Bunkyo-ku, Tokyo 113, Japan.

**) The Photon Factory, National Laboratory for High Energy Physics, Tsukuba, Ibaraki 305, Japan.

***) Bioscience Laboratories, Meiji Seika Kaisha, Ltd., Sakado, Saitama 350-02, Japan. 
enzyme solution contained $50 \mathrm{mg} / \mathrm{ml}$ protein in $5 \mathrm{mM}$ sodium acetate buffer, $\mathrm{pH} 4.5$. The reservoir solution contained 1.3-1.6 $\mathrm{M}$ ammonium sulfate, $50 \mathrm{mM}$ buffer, and DMSO. The concentrations of DMSO examined were $0,1,3,5,7$, and $10 \%(\mathrm{v} / \mathrm{v})$. The enzyme solution $(8$ $\mu l$ ) was mixed with $8 \mu l$ of a reservoir solution, placed on the underside of a glass cover slip over $1 \mathrm{ml}$ of the same reservoir solution in a plastic well, and then sealed.

Preliminary X-ray diffraction experiments were performed using a Huber precession camera with Ni-filtered $\mathrm{CuK} \alpha$ radiation generated by a Rigaku RU-200 X-ray generator $(40 \mathrm{kV}, 70 \mathrm{~mA}$, focus size $0.2 \times 2 \mathrm{~mm})$.

Results. Fig. 1(a) shows the crystals of proteinase A grown in the absence of DMSO at $\mathrm{pH}$ 1.75. Crystals grew to about $1 \mathrm{~mm}$ in length in a few days at $25^{\circ} \mathrm{C}$, or in a week at $4^{\circ} \mathrm{C}$. Under these conditions, only the aggregates of long, thin needles were obtained. The diameters of these needles were less than $20 \mu \mathrm{m}$, so X-ray diffraction data for crystallography could not be collected using such thin crystals.

(a)

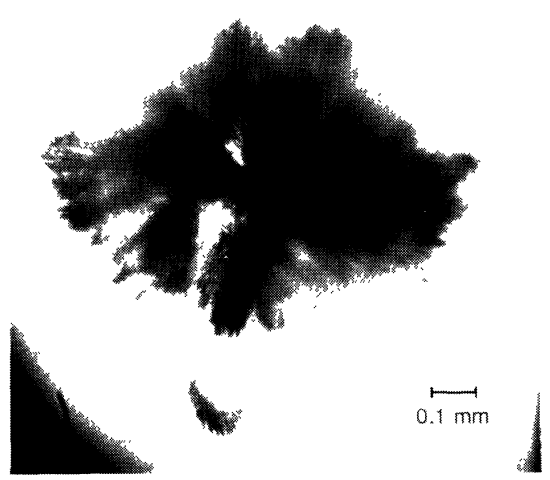

(b)

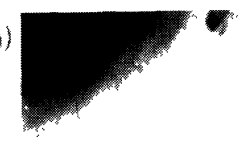

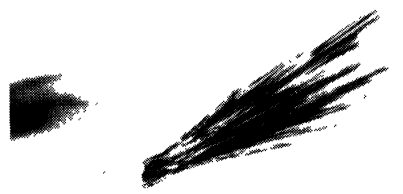

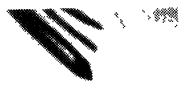

$\stackrel{\leftrightarrow}{0.1 \mathrm{~mm}}$

Fig. 1. Crystals of A. niger proteinase A grown from $1.4 \mathrm{M}$ ammonium sulfate solutions at $\mathrm{pH} 1.75$ (a) in the absence and (b) in the presence of 5\% DMSO.

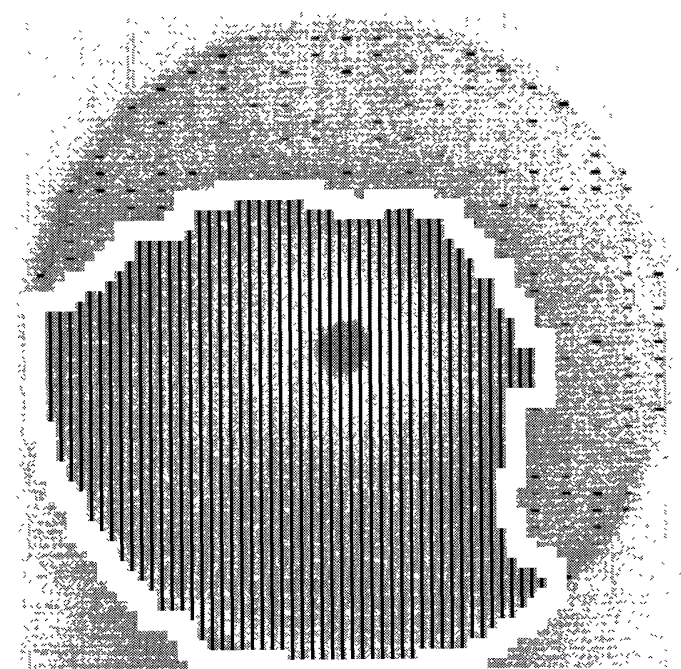

Fig. 2. X-ray precession photograph of the $0 k l$ zone for a crystal of $A$. niger proteinase $\mathrm{A}$ grown at $\mathrm{pH}$ 1.75. The crystal-to-film distance, precession angle, and exposure time were $100 \mathrm{~mm}, 12.0^{\circ}$, and $8 \mathrm{~h}$, respectively. 
When $1 \%$ DMSO was present, rodlike single crystals were grown in addition to the aggregates of needles. As the concentration of DMSO was increased up to 5\%, the single crystals formed grew thicker and more crystals appeared. In solutions containing $5 \%$ DMSO, the size of the single crystals became maximum $(0.15 \times 0.15 \times 1 \mathrm{~mm})$. Single crystals were also grown in solutions containing $3 \%$ or $7 \%$ DMSO, which were almost comparable in diameters to those obtained in a solution containing 5\% DMSO. No single crystals were obtained when the concentration of DMSO was $10 \%$ at $25^{\circ} \mathrm{C}$.

The change in $\mathrm{pH}$ was less effective than that in the concentration of DMSO. At around $\mathrm{pH} 1.75$, thick single crystals appeared in the presence of 1 to $10 \%$ DMSO except for $10 \%$ DMSO at $25^{\circ} \mathrm{C}$. Single crystals obtained at pH between 1.0 and 2.5 had similar thicknesses although fewer single crystals appeared as the $\mathrm{pH}$ of the solution was increased or decreased from 1.75 . The range of $\mathrm{pH}$ in which single crystals were obtained was wider in $5 \%$ DMSO solutions than in $3 \%$ or $7 \%$ DMSO solutions.

The single crystals obtained at $4^{\circ} \mathrm{C}$ and $25^{\circ} \mathrm{C}$ were indistinguishable although the rate of crystal growth was slower and fewer single crystals appeared at $4^{\circ} \mathrm{C}$ than at $25^{\circ} \mathrm{C}$. Crystals grown at $25^{\circ} \mathrm{C}$ were used for the measurements of X-ray diffraction. The typical size of single crystals used was $0.1 \times 0.1 \times 1 \mathrm{~mm}$. An X-ray precession photograph of the $0 \mathrm{kl}$ zone is shown in Fig. 2.

Discussion. The presence of around 5\% DMSO favored the growth of single crystals of proteinase A which could be subjected to the collection of X-ray diffraction data. In contrast, only the aggregates of thin needles were formed in the absence of DMSO. This may be due to the non-specific hydrophobic interaction between proteinase A molecules, and DMSO may weaken such non-specific interaction. ${ }^{10), 11)}$

In additon to DMSO, 1,4-dioxane and poly(ethyleneglycol) 600 were also examined for their effects on the formation of the single crystals of proteinase A. 1,4-Dioxane was less effective than DMSO and poly(ethyleneglycol) 600 was not effective on the formation of thick single crystals. Such differences may be due to the difference in the polarity of these organic compounds, or due to the fact that DMSO is a good precipitation agent for proteins without denaturation. ${ }^{10)}$

As will be detailed elsewhere on the crystallographic data, ${ }^{12)}$ precession photographs revealed that the proteinase $A$ crystals belong to orthorhombic space group $P 2_{1} 2_{1} 2_{1}$ with unit cell dimensions of $a=54.7 \AA, b=70.4 \AA$, and $c=38.0 \AA$.

Acknowledgments. We thank Prof. N. Sakabe (The Photon Factory, National Laboratory for High Energy Physics) for his encouragement and interest during the experiments. This work was supported in part by Grants-in-Aid for Scientific Research from the Ministry of Education, Science and Culture, Japan.

\section{References}

1) Koaze, Y. et al. (1964): Agric. Biol. Chem., 28, 216-223.

2) Chang, W.-J. et al. (1976): J. Biochem., 80, 975-981.

3) Iio, K., and Yamasaki, M. (1976): Biochim. Biophys. Acta, 429, 912-924.

4) Takahashi, K. et al. (1991): J. Biol. Chem., 266, 19480-19483.

5) Takahashi, K. et al. (1992): Structure and Function of the Aspartic Proteinases. Genetics, Structures, and Mechanisms (ed. Dunn, B.M.). Plenum Press, New York, pp. 203-211.

6) Inoue, H. et al. (1991): J. Biol. Chem., 266, 19484-19489.

7) Horiuchi, S. et al. (1969): Sci. Pap. Coll. Gen. Educ., Univ. Tokyo (Biol. Part), 19, 127-139.

8) Ido, E. et al. (1987): Agric. Biol. Chem., 51, 2855-2856.

9) Maita, T. et al. (1984): J. Biochem., 95, 465-475. 
10) Ebashi, S., and Koga, R. (1988): Proc. Japan Acad., 64B, 323-326.

11) McPherson, A. (1990): Eur. J. Biochem., 189, 1-23.

12) Tanokura, M. et al. (1992): J. Mol. Biol., 223, (in press). 